\title{
AGRICULTURE AND RURAL DEVELOPMENT PLANS IN IRAN: SITUATIONS AND PROBLEMS
}

\author{
Farhood GOLMOHAMMADI ${ }^{*}$ \\ ${ }^{1}$ Department of Agricultural Economics and Extension, Islamic Azad University- Birjand Branch - Birjand. Iran
}

\begin{abstract}
Most poor people presently reside in rural areas. The rural poor are exposed to many risks while often lacking instruments to manage them adequately, and so are highly vulnerable. Nowadays sustainable rural development is a pillar and focal point in most discussions for betterment of conditions especially in developing countries such as Iran. After Islamic revolution of 1978, rural development has been gotten very more attention in comparison to previous government namely Shah. But because of many causes such as eight years' war between Iran and Iraq during 1980-1988 and international sanctions against Iran in four previous decades, and also absence of a holistic and systematic view in rural development programs in Iran, many of these plans didn't acquire predetermined goals and objectives in comparing to budget that consumed for them and immigration rate from rural to urban regions didn't decrease. In this article, state a brief and comprehensive discussion about plans, challenges and opportunities of rural development projects in Iran with emphasizing on effectiveness of these experiences and affairs in one of the most disadvantaged regions in Iran namely South-Khorasan province in desert region in east of Iran plus Isfahan province in center of Iran. Results of this study indicate relative successful of these rural development programs in maintaining people in their villages and providing jobs and other facilities for continuing their livings despite near three decades strong drought in these disadvantaged regions. Even though in future policy makers and program planers must consider more holistic, systematic and scientific patterns in their affairs in these domains.
\end{abstract}

Keywords: Development, Agriculture, Rural, Sustainable, Opportunities, Iran

*Corresponding author: Department of Agricultural Economics and Extension, Islamic Azad University- Birjand Branch - Birjand. Iran

E mail: farhood.gol@gmail.com (F. GOLMOHAMMADI)

Farhood GOLMOHAMMADI (iD) https://orcid.org/0000-0003-0939-4678

Received: August 19, 2021

Accepted: October 14, 2021

Published: January 01, 2022

Cite as: Golmohammadi F. 2022. Agriculture and rural development plans in Iran: situations and problems. BSJ Agri, 5(1): 27-39.

\section{Introduction}

Most poor people presently reside in rural areas. The rural poor are exposed to many risks while often lacking instruments to manage them adequately, and so are highly vulnerable (Anderson, 2003). The term "development" has been used in many ways, and there are numerous interpretations of the concept. Among various definitions is the common idea that economic growth is indicative of development (Park and Stokowski, 2009).

Rural development is the process of improving the quality of life and economic well-being of people living in relatively isolated and sparsely populated areas. Rural development has traditionally centered on the exploitation of land-intensive natural resources such as agriculture and forestry. However, changes in global production networks and increased urbanization have changed the character of rural areas (Živkovic et al., 2009).

It is not an exaggeration to say that the battle to achieve the global society's stated objectives on hunger and poverty reduction will be won or lost in the rural areas of the developing countries. Globally, extreme poverty continues to be a rural phenomenon despite increasing urbanization. Of the world's 1.2 billion extremely poor people, 75 percent live in rural areas and for the most part they depend on agriculture, forestry, fisheries and related activities for survival. The promotion of the rural economy in a sustainable way has the potential of increasing employment opportunities in rural areas, reducing regional income disparities, stemming premature rural-urban migration, and ultimately reducing poverty at its very source. In addition, development of rural areas may contribute to the preservation of the rural landscape, the protection of indigenous cultures and traditions while rural societies could serve as a social buffer for the urban poor in periods of economic crisis or social urban unrest. However, public policies at national level and resource mobilization at both national and international levels have not always recognized the multiple potential of the rural economy. Public policies and investments in developing countries have historically favored industrial, urban and service sectors at the expense of agricultural and other rural sector development. In many cases, a coherent rural development policy (by its very nature crosscutting) has fallen victim of the lack of a cross-sectored institutional framework (Anríquez and Stamoulis, 2007).

Among the diverse occupants of rural space, farmers and 


\section{Black Sea Journal of Agriculture}

the rural labor force stand out as the groups most different from their urban cousins, and accordingly are given particular attention here. Needless to say, the close connections between farmers and other business operators in rural areas means that many of the observations made about farmers will have validity for both groups (Anderson, 2003).

The definition of rural development has evolved through time as a result of changes in the perceived mechanisms and / or goals of development. A reasonable definition of rural development would be: development that benefits rural populations; where development is understood as the sustained improvement of the population's standards of living or welfare. This definition of rural development, however, has to be further qualified (Anríquez et al., 2007).

Over the past few decades, many agricultural development projects (ADPs) have been initiated in Iran to alleviate poverty, unemployment, and an insufficient food supply. Although these projects were assumed to be beneficial for rural people, they often had unintended negative impacts on the environment and local communities. The projects were largely unregulated and the impacts often unmitigated. As a result, Iran has suffered from social and environmental degradation in many agricultural areas. Recently, however, ADPs in Iran and elsewhere have been criticized for their detrimental social and environmental impacts at the local level and to the world ecology at large (Ahmadvand et al., 2009).

Iran is one of the largest nations in the Middle East with a land area of around 1.65 million square kilometers and a population in excess of 84 million. About 18.5 million ha extent of Iran are cultivated lands. In Iran, like other developing countries, agriculture is one of the most important economic sectors and comprises a considerably high percentage of production and employment. In Iran 20 million people living in 62000 villages who directly or indirectly depend on agriculture to survive, while most of them are living under poverty line. Still Iranian rural economy is dominated by agricultural sector which accounts for 8\% of GDP, 17.7\% of employment opportunities, $85 \%$ of food supply and $15 \%$ of non-oil exports, plus considerable raw materials for industrial use. Total amount of agricultural productions in Iran is 124 million tons that 83.5 million tons of it contains crop production (Iranian Bureau of Statistics, 2021).

These figures show that rural economy has an important role in national economy. To establish a sustainable economy in rural areas, almost every village needs credit, clean seeds, infrastructure and guidance in crops and livestock production. They also need farm machinery, marketing facilities, cooperatives, water supplies, education and diverse economic activities. For a sustainable and efficient rural development, each village must be provision with all of these inputs and functions. Integration of the functions and efficient management demand an active and sustainable local communities and institutions in Iran. Nowadays, rural sustainability is one of the main issues of sustainable development programs in developing countries such as Iran. Of course not only it is useful to know rural sustainability criteria, but it is also more important to evaluate and prioritize them (Nooripoor and Shahvali, 2011).

In this article, state a brief and comprehensive discussion about plans, challenges and opportunities of rural development projects in Iran with emphasizing on effectiveness of these experiences and affairs in one of the most disadvantaged regions in Iran namely SouthKhorasan province in desert region in east of Iran plus Isfahan province in center of Iran.

\section{Materials and Methods}

Main locations of doing this study were two provinces of Iran, namely South Khorasan province, east of Iran (especially, first rank of doing this study) and Isfahan province, in the center of the country (second rank of doing this study), because of accessibility of them for researcher. Statistical society of the research includes rural people in some selected rural regions in these provinces. For doing this study utilized qualitative approach with its main tools for gathering information such as participatory observation, maps, scientific articles, pictures, documents (Iranian and foreign scientific magazines and journals, TV and radio programs, Iranian Bureau of Statistics), discussion with experts, professors and beneficiaries and field research specially in above two provinces. In below map, shows locations of doing this study as A and B (Figure 1).

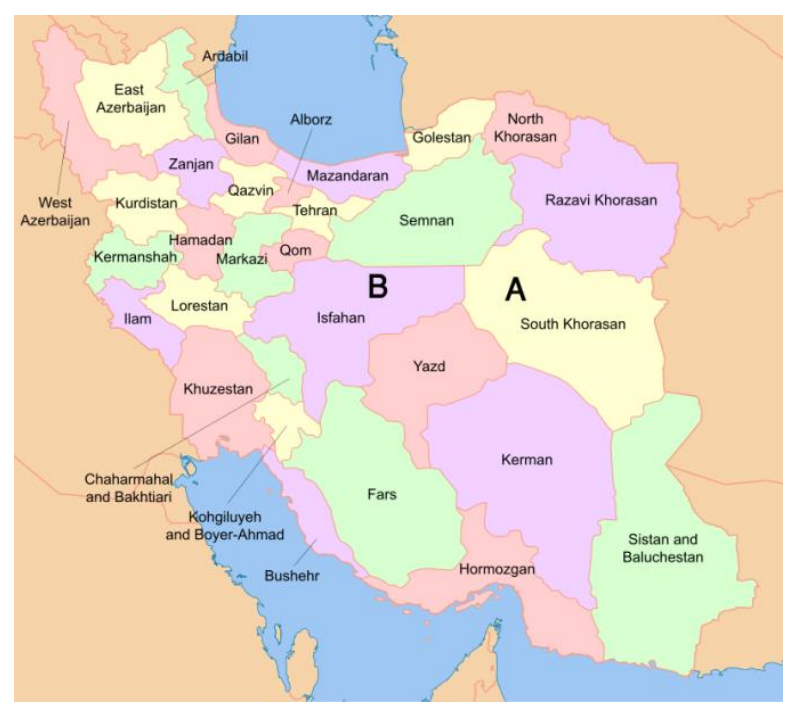

Figure 1. Map locations of doing this study, A (South Khorasan Province, east of Iran) and B (Isfahan province, center of the country) (Iranian Bureau of Statistics, 2021).

As Creswell (1994) noted in a qualitative study, one does not begin with a theory to test or verify. Instead consistent with the inductive model of thinking, a theory may emerge during the data collection and analysis 
phase of the research or be used relatively late in the research process as a basis for comparison with other theories.

\section{Government Organizations in} Agricultural and Rural Development in Iran

Today a large number of government organizations deal with the development of agricultural and other issues in rural areas. The institution which is most influential in rural development is the Ministry of Jihad Agricultural, which is responsible for the agricultural sector, forestry, natural resource, fishery and several rural industries in Iran.

Other ministries are involved with the process of rural development according to their area of activities. This implies the sectored approach in rural development prevails over the territorial approach in Iran. The rural problems are tackled by various government institutions and this requires appropriate coordination among them. Lack of such co-ordination and cooperation among institutions and organizations involved in rural development is a serious problem affecting sustainable rural development in Iran. Thus, the main goal of millennium development in Iran should be focus on methods of sustainable rural development. This depends on addressing the challenges of sustainable rural development in Iran.

Rural population in Iran live in an unstable environment and geographically, villages are extremely diverse and more than $65 \%$ of them have population less than 250 persons, which do not provide sufficient population threshold for most of services and sustainable economic and job creation activities. Only $7.5 \%$ of rural areas have population more than 1000 persons (Kalantari et al., 2008) (Figure 2).

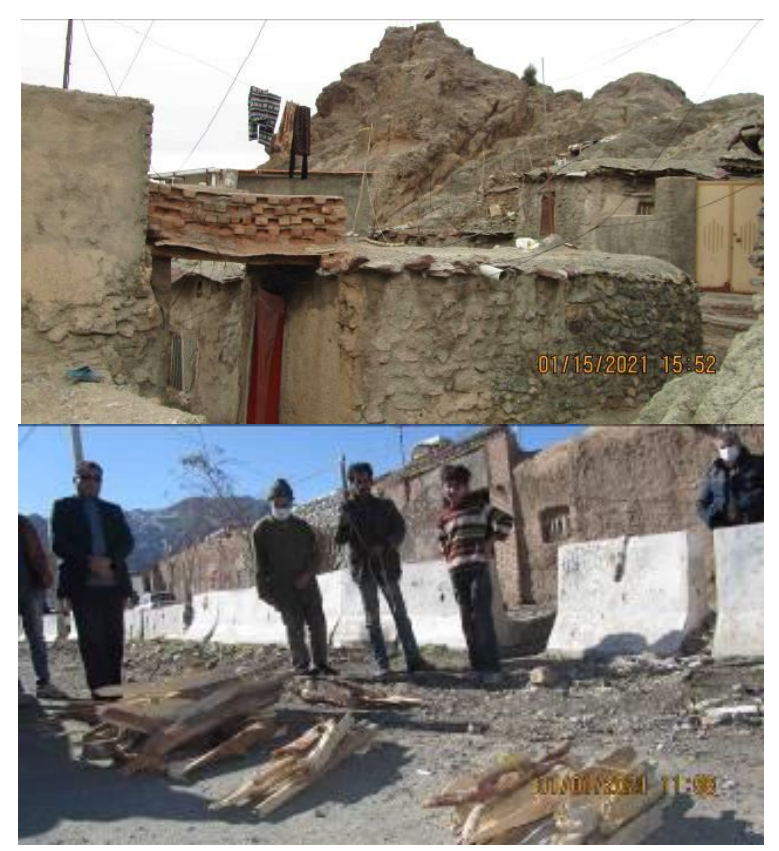

Figure 2. Traditional houses and selling wood by rural people (Pictures by author, January 2021).

\section{Immigration Rural Communities to Large Urban Areas in Iran}

The shift in population from rural communities to large urban areas has been responsible for social - economic changes in Iran. The attraction to urban areas is mostly due to lack of civil services such as educational and health care services as well as adequate job market in the rural areas. Culturally, the issue of urbanization of rural areas has always been looked upon in a negative way because people tend to think that it interferes, implicitly, with the peaceful environment in villages and rural areas would turn into large congested industrial cities. In addition, there are inherent reasons within the socialeconomic infrastructure that promotes slower growth in the rural areas (Ardehali, 2006).

Migration from and to depopulating areas is related to the prospects for rural economic regeneration. The focus is on whether or not migration processes give rise to the necessary human capital required for successful endogenous development. Only by leaving rural areas can young adults acquire the necessary skills to participate in endogenous development, however, few out-migrants subsequently return. In-migrants, while often possessing the necessary human capital to bring about an economic regeneration, are associated with relatively little new job creation. Instead immigration is characterized by self-employment. It is argued that migration is a pre-requisite for rural economic regeneration, but that a rural endogenous development policy on its own will have limited success in regenerating areas experiencing on-going depopulation. Exogenous development strategies are also required (Stockdale, 2006).

Traditionally, labor migration and remittance strategies have been used as a social security mechanism by smallholder households in the absence of insurance markets to cover production risk, and such migration continues to be important in many places (e.g. to cope with drought in eastern India). However, recently, young urban migrants from rural regions tend to neglect their traditional obligations to support their elderly parents, especially if they do not intend to return to their native village, do not expect any sizable inheritance, and have no reciprocal insurance commitment with their parents. These various imperfect mechanisms mean that there may be a case for assisting stressed rural households directly (Anderson, 2003).

The migration processes affecting rural areas are important at a time when endogenous development is advocated. This 'bottom-up' approach requires the presence of local human capital and migration processes will either remove or introduce human capital. Prior research into repopulating rural areas suggests that inmigration brings economic benefits and that quality of life considerations is influential in attracting those with job creation potential. Within the context of rural endogenous development migration is a pre-requisite. It 


\section{Black Sea Journal of Agriculture}

is only by leaving the rural community (out-migration) that young adults are most likely to acquire the necessary skills and knowledge to participate fully in endogenous development (Stockdale, 2006).

Increasingly both academic and government agendas are focusing on the changing structure of national populations. In Iran we observe a rapid decreasing of rural population from 95 percent in 1912 to less than 25 percent in 2021. This lack of Iranian Governments in past century attention to rural demography is particularly significant at a time when rural development policies advocates in their programs. A central aspect of endogenous development is the need for appropriate human capital to be present. Continued outmigration and depopulation, however, are not compatible with endogenous development (Iranian Bureau of Statistics, 2021). Such depopulation is primarily driven by the outmigration of young, often the brightest adults. Much is already known about their decision-making. It is generally acknowledged that the act of migration is beneficial to the individual out-migrant.

Within a given geographical area a variety of migration processes (in, out and return migration) will be evident, irrespective of the overall net migration or population change. With declining natural change variation in population growth rates is increasingly the product of in and out-migration processes. Rural depopulation has been endemic since the beginning of land reformation programs in period of Shah before Islamic revolution 1978 in Iran and recent research confirms its continuation in many parts of Iran despite many investments in past four decades for rural development from Governments in Iran. Many researches indicate that because of absence a holistic and systematic pattern and viewpoint from major policy makers and planners from these Governments in rural development planning, this phenomenon has been caused. The emerging focus on the development consequences of migration for rural communities is particularly timely given that rural economies have undergone a transition from agricultural production to the emergence of consumptive (residence, recreation and environmental conservation) roles (Golmohammadi, 2012).

\section{Credit Arrangements in Rural Areas of Iran}

Informal credit arrangements are widely used in developing countries, since formal lending institutions often do not consider small farmers as credit-worthy. Rural households often attempt to smooth consumption through reciprocal gifts and informal credit. Formal lending institutions in rural areas may be unwilling to lend money to small farmers as the latter may offer collateral in unacceptable forms (e.g. a small plot of land, livestock, etc.). However, informal moneylenders - the landlord, the shopkeeper and the trader - are in a position to accept collateral in exotic forms. In addition, informal moneylenders often have much better information regarding the activities and characteristics of their clientele. Notwithstanding the existence of such informal mechanisms in rural credit markets, rural residents may be considerably assisted in their risk management by interventions that lead to better access to financial instruments by the rural poor (Anderson, 2003).

The great hope in the financial sector servicing the poor in rural areas today is microfinance (MF), which uses much higher interest rates than the subsidized programs, because such instruments must cover the higher costs of collection and risk of default. All types of institutions are used to reach borrowers, including commercial banks, specialized credit institutions, NGOs, grassroots saving groups, cooperatives and credit unions. When the approach is profitable, the private sector becomes involved, and can also then address the demand for noncredit financial services by the poor. The same sanguine fate is, however, still disturbingly distant for the many rural areas where this is not happening. Plagued by poverty, in all the different senses of assets and incomes, residents of these areas will continue to need the types of social protection supports, such as economy-wide safety nets. The challenge will be an on-going one to rural and other development workers (World Bank, 2020).

Similarly, microfinance services are contributing importantly to helping poor people. More generally, having a financial system serving rural areas in a flexible manner that recognizes the riskiness of life in such space is the best single approach to helping all concerned poor people. As rural space is better served by infrastructure, and economic integration within it increases, the absentmarket arguments for intervention will diminish. For the present, however, there are many persistent problems faced by the poor for which policies, institutions and market mechanisms deserve continuing close attention by those concerned with developing rural areas, and with reducing poverty and improving risk management in them.

\section{Urbanization and Land-use Changes in Iran}

Iran as a dry country with limited water and soil resources is also facing several problems for protecting fertile lands and agricultural. It is estimated that urban growth is responsible for degradation of $10 \mathrm{~km} 2$ of farmlands per day in Asian cities. As a worldwide concern, the conflict between urbanization and agricultural land protection is a challenging issue for planners to manage. Such concerns about notorious environmental consequences are caused not only by the area, but also by the spatial arrangement of urbanization process. In other words, policies that only concentrate on the reduction of the area of urban growth may result in undesirable outcomes on welfare and equity of residents, and in contrast, excessive urbanization processes are also 


\section{Black Sea Journal of Agriculture}

responsible for many environmental impacts as well. Conversion of natural and semi-natural ecosystems into impervious surfaces is associated with many other biophysical processes such as salinization, soil compaction, organic matter decline, soil sealing and soil biodiversity decline, which collectively lead to loss of many valuable soil functions and their corresponding services for crop production (Moein et al., 2018; Golmohammadi, 2012; Golmohammadi, 2020).

Urban growth processes in Iranian environments are mainly initiated from rural centers, which are largely surrounded by farmlands and fertile soils. Such proximity between these two utilities can cause conflict between multiple stockholders of different interests, which is normally associated with removal of agricultural fields and productive lands to provide space for more urban construction. In this regard, during the last four decades, the country has experienced $40 \%$ of growth in its population size and urbanism rate, which are also projected to continue during the upcoming decades. Urban expansion on agricultural land-use intensity is associated with a reduction in agricultural land-use intensity and GDP in industrial sector negatively affects farmland intensity. By establishing appropriate socioeconomic and cultural-recreational attractions in areas with lower levels of competition, the pressure of future population growth can be shifted to areas with higher suitability for urbanization and lower competitions with farmlands (Iranian Bureau of Statistics, 2021; Moein et al., 2018; Golmohammadi, 2012; Golmohammadi, 2020) (Figure 3).

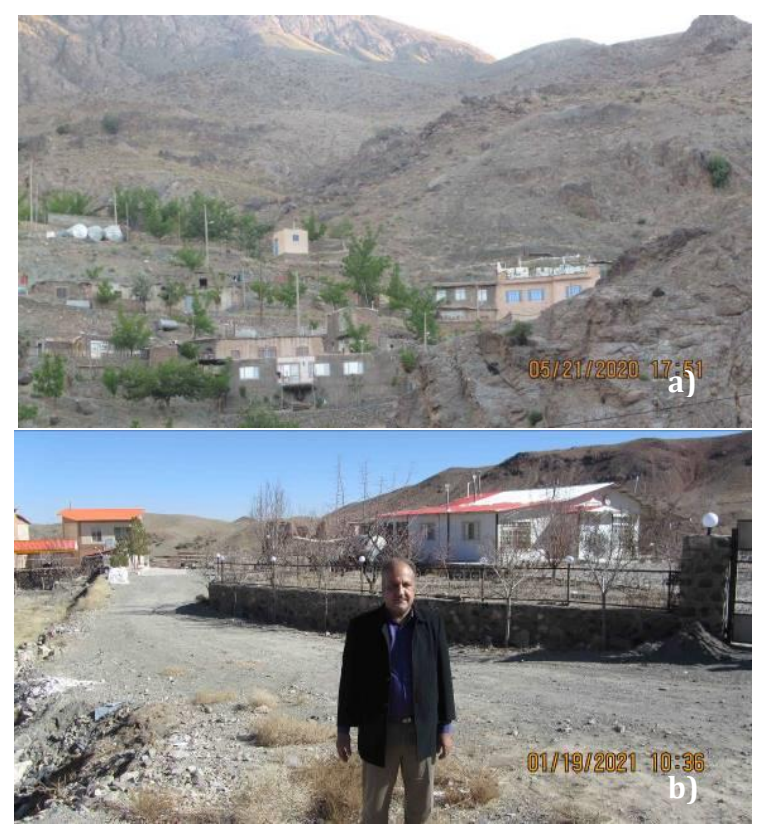

Figure 3. a) In Razg village (12 km distance to Birjand, center of South Khorasan province, east of Iran) (Pictures by author, Summer 2020). b) In Hariwand, Fanood, Kahi and Khorashad villages (25 - $70 \mathrm{~km}$ distance to Birjand, center of South Khorasan province, east of Iran) (By author, January 2021).

\section{Land Fragmentation as a Major Barrier in Rural Areas of Iran}

Land-use efficiency differs according to land use needs, for example, whether the land is used by large agricultural enterprises: associations, cooperatives, research and education establishments or used by smaller or larger private households. Increasing land-use efficiency is a topical issue in many countries; therefore, indicators of land efficiency measurement systems and ways of calculating economic land efficiency are being developed (Cintina and Pukite, 2018; Golmohammadi, 2021).

Low productivity of small-holder farmers, their limited access to land, combined with water shortage, excessive ground water withdrawal, inadequacy of irrigation systems and excessive post-harvest losses, aging farmers with low literacy, who have limited access to quality seeds of improved variety, are main problems in agriculture system in Iran. For them, low productivity interacts with food security conditions (CPF, 2016).

It is true that in traditional systems, fragmentation had some advantages, but under an agricultural renovation condition, fragmentation is a serious limiting factor. It causes a high increase in costs and makes productivity improvement activities uneconomical. Therefore, consolidation of fragmented plots of lands for achieving optimum size and shape of farmland, directly affects productivity. The experiences of different countries confirm this claim. In view of these considerations, numerous land consolidation and land reform policies have been implemented to reduce fragmentation in European countries like the Netherlands and France, in African countries like Kenya, Tanzania and Rwanda, and elsewhere. Small landholdings were well-adapted to Iran's agriculture sector. With increasing population pressure and more efficient technology, they are coming under increasing strain. In the long run, they may be not adaptive at all. Therefore, for economic crop production, it is necessary to execute land consolidation programs that can provide appropriate living standards for farmers. According to some studies, the optimum farm size for economic crop production should be at least 12 ha. Summarizing these arguments, land fragmentation is considered as one of the major obstacles to achieve sustainable rural livelihoods, in Iran. Accordingly, the extensive arrays of smallholdings need to be restructured and consolidated. A better understanding of the causes of land fragmentation in Iran is needed, especially now that the country is confronted with the challenge of agricultural modernization resulting from its entry into the World Trade Organization (WTO) etc. (Lahsaeizadeh, 2007; Kalantari and Abdollahzadeh, 2008; Golmohammadi, 2021) (Figure 4). 


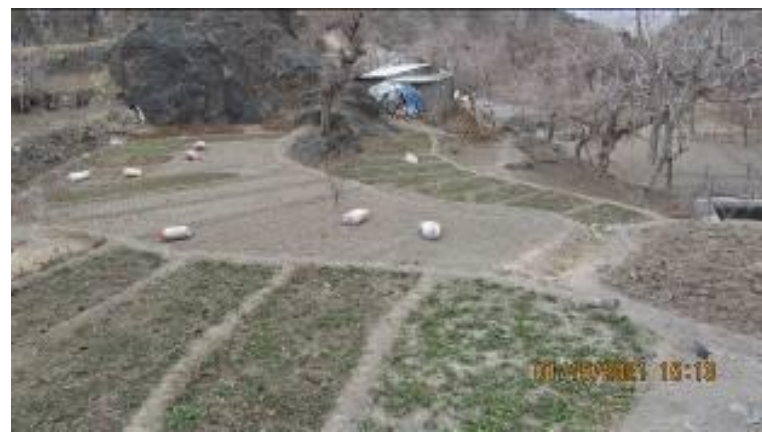

Figure 4. Land fragmentation, peasantry and small holdings as major type of agricultural production system in Razg, Kaseh Sang and Amir Abad Sheybani villages, (7$12 \mathrm{~km}$ distance to Birjand city, center of South Khorasan Province, east of Iran) (Pictures by author, January 2021).

\section{Inequality in Regional Development of Iran}

Regional planning in Iran during the first decade following the Revolution (the 1980s) was based on reducing the development gap between different regions and creating a relative balance in regional development, special attention to the backward areas, control of urban and rural system, control of irregular expansion of the cities and control of physical enlargement of the urban areas, preparing the foundation for hierarchical distribution of services and infrastructure in the entire territory. In the second decade after the Revolution (beginning in 1999), a new direction appeared in the regional planning. The main differences include:

A. Change of the direction of regional planning from national and interregional levels to intra-regional, regional and sub-regional levels.

B. Increased attention to organizing plans for rural areas.

C. Attention to identifying potential and capacities of regions for development (Afrakhteh, 2006).

Conceptually, two approaches have been manifested in Iranian regional planning. One holds regional planning to be a kind of continuation of architecture and the other believes regional planning to be a policy for economic development or an expansion of social justice. Following these two approaches, the regional planning process has been in practice unable to identify the real needs and priorities at different regional levels and consequently their application in responding the needs of the region have been hampered.

On the other hand, the weakness of traditional methods of planning and the ambiguous legal position, responsibility and manner of providing regional plans, and lack of a clear task division among the relevant departments have, in practice, resulted in interdepartmental rivalries and caused parallel movements in compiling regional plans and programs which in the end has hampered their success (Afrakhteh, 2006).

In Iran we saw inequality in regional development. In justifying this regional inequality, some pinpoint the lack of natural resources in various areas. This is mainly claimed by the studies carried out by foreign consulting companies, including Ital Consult. Such studies do not account for the reality that regional inequality was not so marked earlier in the century and why Tehran-which is not comparable in terms of natural resources with, say Khuzestan-has enjoyed a much higher development rate. It is clear that natural resources are an important factor; however, in the absence of a clear and specific policy, they cannot account entirely for a region's development status. Some other commentators attribute the regional inequalities in Iran to ethnic and cultural differences and identify a significant relationship between those and the development of the nation's regions. In response to this, it can be said that while ethnic and cultural differences are not a new issue, regional inequality in its contemporary acute form is a new phenomenon. Yet another approach holds that the country's regional inequalities are related to the limitations of regional markets and the market-oriented nature of Iranian industries. It is clear, though, that such an analysis is addressing the effects rather than the causes of the problem. The Iranian leftists have emphasized international relations, unequal relations between the regions and legacies of imperialism as the significant factors causing regional inequality (Figure 5, Figure 6 and Figure 7).

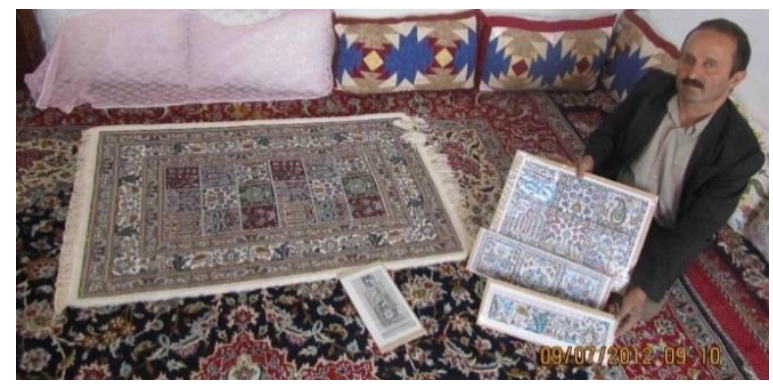

Figure 5. Carpet weaving in rural house as a main instrument for helping household economy in a disadvantaged rural region (Zirg village, $50 \mathrm{~km}$ distance to Birjand, center of South Khorasan province, east of Iran) (By author, October 7, 2012).

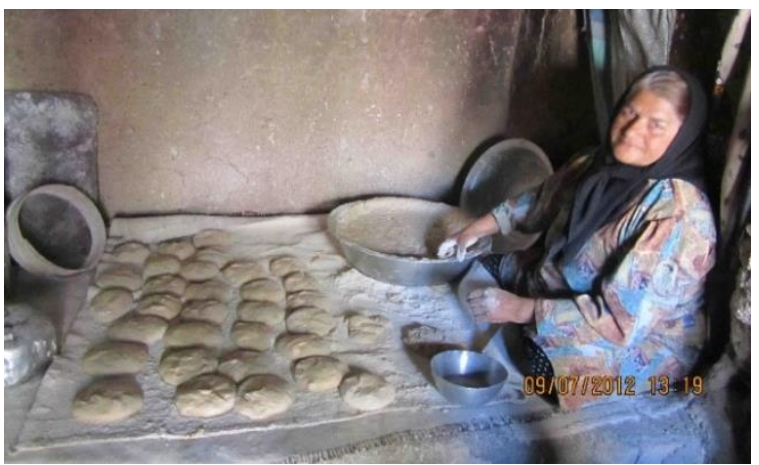

Figure 6. Baking bread in a disadvantaged rural region (Zirg village, $50 \mathrm{~km}$ distance to Birjand, center of South Khorasan province, east of Iran) (October 7, 2012). 


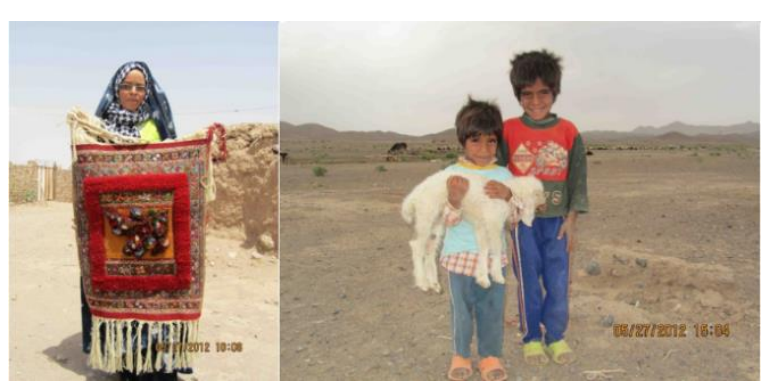

Figure 7. Nomadic lifestyle people and their traditional woman carpet weaver and children with poor health and education conditions in a disadvantaged and dried region near Qaen, $110 \mathrm{~km}$ distance to Birjand, center of South Khorasan province, east of Iran (By author, May 27, 2012).

\section{Drought and Its Effects on Rural Development in Iran}

Information pertaining to a decrease or increase in the amount of rainfall have significant effects on agricultural and municipal water management, especially in arid and semi-arid countries like Iran. Since rainfall is the most important source of water for all agricultural requirements, information about rainfall trends is valuable to policy makers (Ghahraman and Taghvaeian, 2008).

According to latest report that published by National Drought Warning and Monitoring Center (NDWMC) in the year 2020 - 2021 the average amount of rainfall in country determined $127.1 \mathrm{~mm}$ that it means it is very lower (about 50 percent) from the long run average precipitation of the country that is $215 \mathrm{~mm}$ per year (National Drought Warning and Monitoring Center, 2021).

Arid and semi-arid zones are very sensitive and vulnerable to the climate change impacts. Vulnerability to climate change and other hazards constitutes a critical set of interactions between society and environment. The central Asia is particularly vulnerable due to physical geography, which dominated by temperate deserts and semi deserts. Aridity is expected to increase across the entire Central Asian region. Temperature increases are projected to be particularly high in summer and fall, accompanied by decreases in precipitation.

I.R of Iran is located in the North Temperate Zone which lies between the latitudes of $25^{\circ} 14^{\prime}$ and $39^{\circ} 42^{\prime} \mathrm{N}$ and the longitudes of $44^{\circ} 10^{\prime}$ and $63^{\circ} 11^{\prime} \mathrm{E}$ with a total area of approximately 1650000 square kilometers. Elevations range from 26 meters below sea level on the shores of the Caspian Sea to 5671 meters above sea level at the pick of the Mt. Damavand. Drought is one of the most critical factors in Iran. About $50 \%$ of Iran can be classified as arid or semi-arid zones. There is not a good annual rainfall distribution in most regions of Iran. Not only high temperature in southern, central and lowlands of Iran is a limiting factor, but also low temperature in northern, western and highlands is another limiting factor too. In the South Khorasan province, a greater portion of land during last decade became warmer than before. This confirmed the overall global warming in the world. The results derived from the trends of climate index confirmed this fact that the overall climate of the province became worse because more than $76 \%$ of the lands showed that the region goes to the drier condition (Masoudi et al., 2018).

Iran long-term average annual rainfall is in the range of 224-275 mm/year, making Iran one of the most arid regions of the world. By way of comparison, annual precipitation in Iran is less than one third of the world average (ca $990 \mathrm{~mm}$ ). The lack of water is a major limitation for agricultural development. The pressure on water resources is increasing as demands for water consumption expand. Increases in population, socially demanded rises in living standards, and the expansion of irrigated agriculture have drastically increased water use to the extent that the sustainability of the water resources of Iran is being threatened. Agriculture typically utilizes around $90 \%$ of Iran's total water consumption, of which around half is from surface resources and half from groundwater reserves. Drought is directly affecting more than 2.6 million hectares of irrigated farms and 4 million hectares of rain-fed agriculture. A national assessment of water utilization identified that the rate of extraction from aquifers was more than what was permitted in 223 plains (Keshavarz et al., 2013).

Iranian rural and nomadic communities living in drought-prone marginal areas with subsistence economy seem to be most vulnerable during the occurrence of drought crisis. A severe drought which has been unparalleled during the last 30 years, seriously affected most provinces, mostly in southeastern and central Iran. This drought has continued since then in the provinces of Sistan and Baluchistan, South Khorasan and Kerman, affecting all aspects of socio- economic life and has seriously caused damages to environment and natural resources (Golmohammadi, 2012; Hosseini et al., 2009). Production of rain-fed wheat and barley has been significantly reduced, by 35-75\%. Agricultural losses in irrigated areas have also been severe, with about 2.8 million tons reduction in wheat production and 280,000 tons in barley per year during the drought, as well as the loss of the value of stubble as fodder. Production of alfalfa was down 38\%. Many fruit trees (e.g. banana plantations in Sistan and Baluchestan province) have perished and 1.1 million hectares of orchards growing almonds, apricots, mangoes and other fruits have been heavily affected. The drought severely affected the number and productivity of commonly-raised livestock as it reduced the quantity and quality of forage available on rangelands and pastures. Over 85 million head are affected by the drought. Over 200,000 nomadic herders have lost or continue to lose their only source of livelihood and an estimated 800,000 small animals have died due to malnutrition and disease (Keshavarz et al., 2013). 


\section{Black Sea Journal of Agriculture}

As a result, precipitation pattern including rain and snow will change. Other facts and projections show, warm and dry regions will become warmer and drier (Masoudi et al., 2018).

Since farming is the primary source of income for most farm families, low precipitation and depletion of groundwater has led to a major reduction in income. Less vulnerable families experienced a loss of income due to reduced area of cultivation and because of pest infestation.

Most of less vulnerable families could only cultivate about a third of their land. Resource poor families believed that their production was down by about $60 \%$. The prolonged drought had created significant hardship for them. The very resource-poor families faced many obstacles. Their farm income approached zero. Poor soil, lack of irrigation water, money, tools and equipment intensified their hardship during drought. It is important to note that some of very resource - poor families relied on charitable organizations, like the Imam Khomeini Relief Committee, to survive. Obtaining money from their very limited resources and savings, and the impetus to quit farming as a consequence of the drought, led to an increase in their dependency on government support. Without the assistance of the government and NGOs, many would be in a much more precarious position. As an extreme natural hazard, drought has various impacts at local, regional and national levels, including:

A. Economic impacts: such as loss of farm income and reduced income diversity, increased debt, increased on-farm workload and decreased options for offfarm employment.

B. Basic needs: including food insecurity and health problems due to drought related stresses and lack of income for adequate health care.

C. Education: reduced household expenditure on education, which can especially affect younger members of families who may forego the opportunity to continue their education due to economic constraints.

D. Marriage: an increase in the age of marriage and a change in mate selection criteria.

E. Conflict and dependency: including increased family and social conflict, social isolation and increased dependency on government assistance.

F. Emotional and psychological: including suffering from a sense of hopelessness, failure and loneliness.

These impacts are not the same for all families. This indicated that farm families could be classified into two distinct groups:

A. The less vulnerable and

B. The more vulnerable.

The vulnerable families have suffered more and their resilience has dramatically diminished. It is important to be aware of the gendered and age differential nature of drought and how this plays out in relation to the above impacts. In vulnerable families, some impacts like unemployment, increased on-farm work, malnutrition and hunger, loss of education opportunities, marriage difficulties, social isolation, social and family conflict, depression and hopelessness are disproportionately experienced by women, children and older people.

The limited access to the job opportunities in droughtaffected rural areas led to an increase in unemployment, and in some cases, to people seeking work elsewhere. This experience encourages the young people of vulnerable families to want to never return to the farm. This loss of the next generation of potential farmers may lead to an undeveloped form of agriculture that is more vulnerable to future droughts and other natural disasters. Therefore, support should be provided to increase the resilience of young people and to allow them the choice to continue farming in the rural areas (Keshavarz et al., 2013) (Figure 8 and Figure 9).

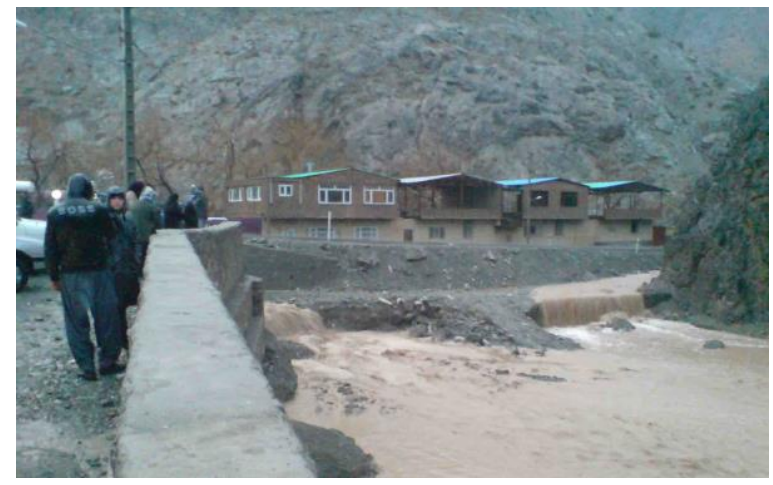

Figure 8. Floods and their damages that caused loss of valuable water after a long period of drought in South Khorasan province, east of Iran (By author, February, 2012).

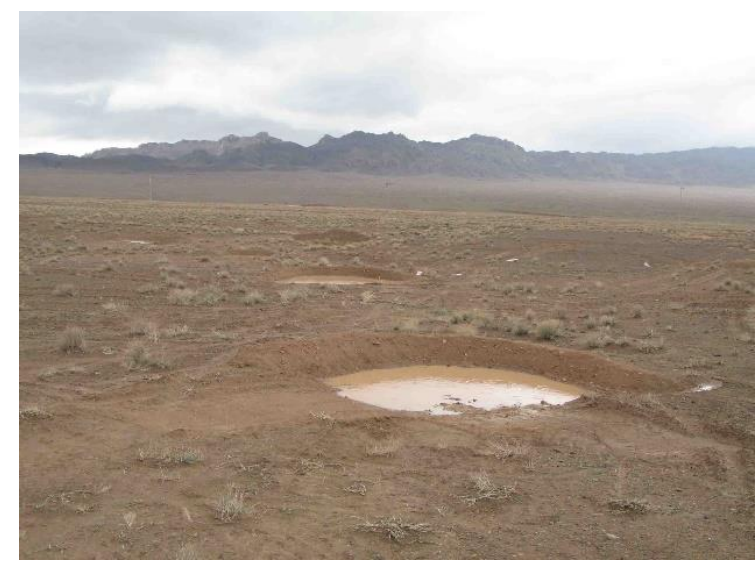

Figure 9. Some watershed management projects for saving valuable water of floods for confronting to long periods of drought in South Khorasan province, east of Iran (By author, 2010).

\section{Establishing Infrastructures in Rural Regions of Iran}

In the late 20th and early 21tt centuries, rural restructuring has been identified in Western Europe, North America, and some countries in the Middle East. At the same time, such transformational development has 


\section{Black Sea Journal of Agriculture}

also taken place in the rural areas of developing countries, such as China, India, the Philippines, Zimbabwe, and Ecuador. This rapid and radical rural restructuring is often referred to as rural transformation development (RTD). In most developing countries, RTD is usually characterized by changes in agricultural intensity, crop selection patterns, farmland, land productivity and farm income, labor and technological productivity, and major improvements in rural housing and economic and social conditions resulting from industrialization and urbanization. RTD is, in essence, a term that captures changes in traditional rural industries, the employment consumption structure, and the social structure. These changes signify a transformation from previously isolated urban and rural economic structures toward more coordinated urbane rural development. Such transformation radically changes the urban - rural relationship and the relationship between agriculture and industry. On balance, as development proceeds, risk management in rural space should become less needed, and in some sense, easier. Particularly as the private sector develops in its many service roles in rural areas, there will be less need for governments even to ponder intervention for agricultural and other rural development purposes.

RTD assessment involves measuring three major components:

- The development of a distinctively rural economic system;

- The transformation of rural social, economic and consumption structures;

- And the improvement of the urbane rural relationship (Long et al., 2011).

The advantages of diversification or rural development have long been recognized and the newest role of the government has been to encourage and whenever possible assist in these endeavors. Nearly, half of the world's population lives in the rural areas of the developing countries. Rural areas in Iran include vast geographical areas with small towns and villages of one thousand or less in population dotting the landscape. These small communities are necessarily linked to agriculture with very little diversification. These communities are solely dependent upon the fortunes of one or two primary enterprises that are in many cases controlled by actions a thousand kilometers away. This is an extremely tenuous situation and these communities must diversify to insure economic and social viability. The advantages of diversification or rural development have long been recognized and the newest role of the government has been to encourage and whenever possible assist in these endeavors. For that purpose, several electrification and piped-water projects and supporting programs have been undertaken by the Ministries of Energy (MOE). The programs, which attempt to address problems aggravated by the recent war, distance, and low population densities, depend upon the will and determination of the people involved as well as the wise and effective use of energy conversion and distribution technology for success. There are many social and economic benefits that are gained from the use of needed technology for rural energy development in Iran. To realize some of these benefits is an ongoing and changing process that must be sensitive to the specific technology itself and its potential for effective change or improvement (Ardehali, 2006).

Radio, television, media, satellite technologies and improved road and transportation facilities and technologies in relation to agricultural industry in recent years provided in rural areas (Jalalia et al., 2011).

\section{Establishing ICT Centers in Rural Regions of Iran}

Rural Information and Communication Technology Centers (ICT Centers) play an important role in rural development through improving e-governance in rural areas. ICTs can enable rural communities, particularly in developing nations with an opportunity to meet development goals such as poverty reduction, basic health care, and education far more effectively than ever before. Using ICTs in rural areas for enhancing agricultural production is suggested to be immensely beneficial as most of the poor live in rural areas. Moreover, ICT application in rural areas can give them a voice and improve their employment. International policies always call on under developed countries to create simple tools for local development. In Iran, information technology service-providing centers and centers for rural communications were established thanks to popular support and backing from state-run organizations. 17,000 Tele-centers are currently active and equipping them until 2020 was a major effort of the government of Iran to develop electronic services which can balance cities and villages in cultural, social and economic development. The role of Tele-centers in Gharnabad and East Livan (2 pilot villages in ICTs application in rural development in north of Iran in Golestan province) for improving knowledge in general and making a good media for business development and entrepreneurship is proven. (Jalalia et al., 2011; Golmohammadi, 2012; Iranian Bureau of Statistics, 2021).

\section{Main Barriers for Rural Development in Iran}

The main factors responsible for slow rural development in Iran are identified as:

A. Lack of understanding for importance of energy (heavily subsidized fossil fuel and electrical energy).

B. Low and inconsistent income (nature of government-supported job market).

C. Lack of proper management and adequate basic infrastructures for energy matters (inadequate legislative support).

D. Uneven development within the country 
(investment mainly in the government holdings).

The causes for slow development are inter-related and they form a closed cycle making it difficult to approach problems on individual basis. Of course, the key factor contributing to this phenomenon is the uneven development at the global scale $(87 \%$ of the economy managed by the government of Iran). The slow development, consequently, results in the rural - urban migration, depleting the rural areas of the valuable manpower resources, as it is commonly conceived that the move to urban areas is a remedy for economic problems found in the rural areas (Ardehali, 2006).

\section{Approaches for sustainable rural community development in Iran}

Today it is clear that rural communities face with various challenges in achieving a sustainable development. It seems that sustainable rural community development in Iran can be achieved through:

A. Diversification of rural economy and capacity building of rural communities

B. Supporting job creation activities and promoting sustainable tourism, business and industrial activities based on rural social and economic potentials

C. Encouraging people for participating in the process of planning, executing and maintaining rural development projects

D. Establishing an appropriate urban-rural network to serve rural areas by small towns

E. New economic policy needs to be established encouraging micro-enterprise supported by microcapitals and national policy must secure, protect and improve rural livelihoods

F. A new rural sector strategy has to be prepared that incorporate the following objectives: structural change to the production system, with suitable utilization of productive resources and environmentally friendly technologies, sustainable managed resources; no urban bias in health, education and safe water provision; off-farm income and employment generation; decentralized and participatory decision making; functioning rural markets; and widely shared rural economic growth (Kalantari et al., 2008; Golmohammadi, 2012).

\section{Participation of Local People toward Rural Development}

Today exploiting the participation and the abilities of local people, particularly rural population, toward rural development has been considered as one of the effective strategies toward sustainable and comprehensive development of rural areas. The most important tool to achieve this goal is establishing NGOs based on the needs as well as abilities of different groups living in the villages, in diverse and essential issues of indigenous and local environment, in order to perform rural developmental programs. These organizations, in economic and social fields - due to avoid a complex public sector bureaucracy and profit making of private sector - made it possible to in such areas as fighting poverty and hunger, environmental protection, forestry, increase awareness general welfare, health, community and family, according to women and children, redacting social damages and act successful than the private and public sectors. Villages in the contemporary developments and threats facing widespread, and therefore ensure continuity of rural life and survival requires solutions and new methods to deal with problems that are innovative, invent, create products, processes and techniques depend on is large. For this purpose, managers must take on roles that are peripheral to suit changing conditions. Thus, rural development compared with the last link with the concept of entrepreneurship has wider. In recent years, the Islamic Councils and rural workers have been defined as the new managerial bodies in villages in Iran. As local peoplecentered managerial entities that are direct responsible bodies in villages, Rural workers and Islamic Councils can make policies, manage and implement various educational programs, help the development of necessary infrastructures, attract financial resources, and play a major role in the development of rural entrepreneurship, paving the way for the development of rural entrepreneurship in Iran. Essentially, the two factors of entrepreneurship are determined as opportunity and desire to become entrepreneurs. The main factors driving opportunities include: internal entrepreneurial abilities, attempting to investment, market entry and general macroeconomic environment (Golmohammadi, 2012).

\section{Measuring Agriculture and Rural Development}

Under the emerging rural development paradigm, we argue that to be multifunctional an activity must add income to agriculture, it must contribute to the construction of a new agricultural sector that corresponds to the needs of the wider society and it must reconfigure rural resources in ways that lead to wider rural development benefits. The concept of the multifunctionality of agriculture embraces all goods, products and services created by farming activities. Used for the first time in 1993 by the European Council for Agricultural Law in an effort to harmonize agricultural legislation across Europe and to provide the general notion of 'sustainable agriculture' with a legal definition (Marsden et al., 2008).

Issues related to measuring rural development have attracted the interest of a wide variety of researchers. During the 1970s and 1980s, an index of rurality for local government districts in England and Wales was developed to identify some of the differences between degrees of rurality. This index included such indicators as 
population, household amenities, occupational structure, commuting patterns, and the distance to urban centers, and was constructed using a range of statistics from the 1971 and 1981 censuses. It is important to note that Paul Cloke (1994) himself has since drawn critical attention to the inappropriate or naive method of indexing and categorizing the rural in this way. He has written extensively on representations of the rural, social constructionist approaches to rurality, and considerations of how the rural is produced by social, cultural, material and economic relations. A similar rurality degree index (RDI) was recently established to distinguish degrees of rurality in eastern coastal China. A corresponding index has also been developed to measure and explain both urban and rural development (Long et al., 2011).

\section{Conclusion and Recommendations}

The oil industry has been exploited for the past 60 years in Iran. It has been shown that oil and development have direct influence on one another; the fluctuation of oil process, its rise and recession, has a great effect on the nation's developmental trend. Relying solely on nonrenewable energy sources like oil can become a cause of unsustainability by itself. Iran's population has increased and simultaneously the residency pattern has favored the urban areas in the last decade. Urbanism increase is an important index of progress in parallel with the production and growth of economy. However, urbanism evolution in Iran is not the result of social and economic streamlining, rather the intensification of the gap of the expected incomes between urban and rural areas, seasonal drought and the availability of the resources (Bakhoda et al., 2012).

Rural development has traditionally been seen as a vague term that is difficult to specify measure and evaluate. Today's rural economy and its social system are much more diverse, complex, sophisticated and global than those of the last century. Rural development is now seen as a multilevel, multi actor and multifaceted process that requires an understanding of the agricultural developmental model, the relationship between agriculture and society, the regional socioeconomic structure and rural economic status, individual farm households and their behaviors, and local policies and institutions. (Long et al., 2011).

Iran is a nation with strong rural roots. Despite rampant urbanization, about $25 \%$ of its population still lives in rural areas, and the national economy has been built on agricultural foundations since ancient times. Currently, both rural development and urban development in Iran are experiencing a transition period. Since the overcoming great Islamic revolution in 1978, the Iranian central government has focused significant attention on substantially improving rural residents' well-being and achieving the coordinated development of urban and rural areas. Improving rural residents' well-being is a popular and political concern in Iran (Golmohammadi,
2012; Iranian Bureau of Statistics, 2021).

Rural areas in Iran are necessarily linked to agriculture with very little diversification. These communities are solely dependent upon the fortunes of one or two primary enterprises. This is an extremely tenuous situation and these communities must diversify to insure economic and social viability (Ardehali, 2006).

A useful theoretical approach to rural development considers how local factors and external driving forces interact to determine the development of the rural economic system. This relationship between the local, rural system and the external system in particular, the links between the rural and urban economies and cultures are important strands in current rural development research. For instance, rural agricultural development has been seen to play an important role in regional industrialization and urbanization by guaranteeing the supply of food and raw materials needed to sustain industrialization. This kind of role, in turn, leads to the transition and transformation of rural areas (Long et al., 2011).

Overall situation in economic challenges indicates that the rural economy in Iran is too much depending on agriculture. The poor agricultural infrastructure and lack of forward and backward linkages, that hinders the development of other industries, are the main obstacles towards diversify and sustainable economic development of Iranian rural communities. Lack of indigenous and appropriate theoretical framework and coherent strategy for sustainable rural development accompanied by centralized planning system indicates basic management and planning challenges which create pronounced obstacle for involving people in planning process. People participation in local management system and planning process should become in the core of development plans and this requires decentralization of planning system for rural areas. In the process of decentralizing, rural areas should have higher level of authority to participate in planning process. Environmental challenges are emerged in the form of overexploiting of underground water resources and use of unsuitable technology in agricultural sector. As Iran is located in arid and semiarid areas, there is a growing risk of droughts in most parts of the country, which will further slowdown the economic performance of the country in general and agricultural sector in particular. This indicates that ecological and environmental sustainability should be considered in policy making and planning system in Iran. Wide dispersion of rural settlements accompanied by insufficient population threshold indicates physical challenges for rural areas in Iran. This pattern of settlement system does not allow providing any social services as well as diversifying economic activities in many rural areas. Finally, absence of rural-urban linkage and inability to localize these linkages is one of the greatest challenges in promoting a more dynamic process of rural-urban development in most provinces in the country. Due to lack of such policy, disparities occur, as 


\section{Black Sea Journal of Agriculture}

higher value added in processing is captured in national core metropolitan regions. This phenomenon not only creates a fundamental barrier for achieving sustainable development, but generates a deep rural urban disparity in the country (Golmohammadi, 2012).

Despite considerable achievements in the provision of basic developmental facilities in terms of drinking water, access to primary healthcare services, high-quality and nutritious food, social services, and proper housing facilities, there are many rural and slum communities in Iran where these essential needs remain unfulfilled. Lack of equity is prominent, as large differences exist in underprivileged provinces. New policies developed in the past two decades have resulted in substantial achievements in meeting population needs and reducing the socio-economic gap; nevertheless, poverty levels, unemployment due to a large increase in the birth rate in the early 1980s, and lack of community participation are matters yet to be addressed. To overcome these deficiencies, a basic development needs approach was adopted to promote the concept of community self-help and self-reliance through inter-sectored collaboration, creating an environment where people could take an active part in the development process, with the Iranian government providing the necessary support to achieve the desired level of development (Asadi-Lari et al., 2005). In order to increase the prospects for return migration changes need to take place within rural communities, none more so than the creation of employment opportunities consistent with the individuals' level of qualifications. Of course in - and return migration indirectly stimulate demand for rural services, among other things, and consequently contribute to the survival of depopulating communities. However, if these communities are to do more than merely survive, greater economic regeneration is required. It is for these reasons that a rural endogenous development policy on its own will have limited success in regenerating depopulating areas. The fact that some of the respondents have created jobs indicated that some level of regeneration is taking place, but this needs to be intensified.

Development policies need to assist and in particular more fully take account of the migration processes operating in rural peripheral areas in Iran. Initially, at least, it is suggested that the emphasis will need to be on exogenous development creating the economic opportunities to encourage return and in-migration flows. Equally important retention policies will be required. Economic programs should not override the fact that the objectives for economic development must still originate from within the local community.

Exogenous measures of support should therefore enable rural communities to achieve their goal of economic regeneration. While at a national level government and academic attention is focusing on population dynamics and positive migration policies, one should not forget that the current national problems of population decline and ageing have existed among some rural communities for a considerable time. The introduction of national migration policies should also be accompanied by positive rural migration policies, especially for depopulating peripheral areas. Such policies should aim to encourage the immigration, return and retention of much needed human capital to enable endogenous development. It is also incompatible with the need to move to acquire the relevant skills and experience to contribute to endogenous development. Various researches have demonstrated that quality of life perceptions are important in attracting migrants with business ideas. Addressing the quality of life perceptions associated with declining peripheral areas may do much to encourage the inflow of those with job creation and economic regeneration potential in Iran (Stockdale, 2006; Golmohammadi, 2012).

\section{Author Contributions}

All task made by single author and the author reviewed and approved the manuscript.

\section{Conflict of Interest}

The author declared that there is no conflict of interest.

\section{References}

Afrakhteh H. 2006. The problems of regional development and border cities: A case study of Zahedan, Iran. Cities, 23(6): 423-432.

Ahmadvand M, Karami E, Zamani GH, Vanclay F. 2009. Evaluating the use of Social Impact Assessment in the context of agricultural development projects in Iran. Environ Impact Asses Rev, 29: 399-407.

Anderson JR. 2003. Risk in rural development: challenges for managers and policy makers. Agri Sys, 75: 161-197.

Anríquez G, Stamoulis K. 2007. Rural development and poverty reduction: is agriculture still the key? ESA Working Paper June 2007; No. 07-02. Agricultural Development Economics Division the Food and Agriculture Organization of the United Nations. URL: http://www.fao.org/es/esa (access date: May 05, 2021).

Ardehali MM. 2006. Rural energy development in Iran: Nonrenewable and renewable resources. Renew Energy, 31: 655662.

Asadi-Lari M, Farshad AA, Assaei SE, Vaez Mahdavi MR, Akbari ME, Ameri A, Salimi Z, Gray D. 2005. Applying a basic development needs approach for sustainable and integrated community development in less-developed areas: report of ongoing Iranian experience. Pub Health, 119: 474-482.

Bakhoda H, Almassi M, Moharamnejad N, Moghaddasi R, Azkia M. 2012. Energy production trend in Iran and its effect on sustainable development. Renew Sust Energy Rev, 16: 13351339.

Cloke P. 1994. Enculturing political economy: a life in the day of a 'rural geographer'. In P. Cloke, M. Doel, D. Matless, M. Phillips, \& N. Thrift (Eds.), writing the rural. Five cultural geographies. Paul Chapman Publishing, London, UK, pp: 41.

Creswell JW. 1994. Research Design, qualitative \& quantitative approaches. SAGE Publications, London, UK, pp: 381.

Ghahraman B, Taghvaeian S. 2008. Investigation of annual rainfall trends in Iran. J Agric Sci Technol, 10: 93-97.

Golmohammadi F. 2012. Sustainable agriculture and rural development in Iran, Some modern issues in sustainable 


\section{Black Sea Journal of Agriculture}

agriculture and rural development in Iran. LAP Lambert Academic Publishing. Chisinau, Moldova, pp: 176.

Golmohammadi F. 2020. Land use changes in natural resources and rural areas: Great threats for sustainable development in Iran. BSJ Pub Soc Sci, 3(2): 59-67.

Golmohammadi F. 2021. Land Fragmentation in Confronting to Sustainable Agricultural Development and Food Security in Iran. BSJ Pub Soc Sci, 4(1): 1-10.

Hashemi SS, Motiee Langerudi SH, Ghadiri Masoom M, Rezvani MR, Moghimi SMA. 2011. Performance review of rural workers and islamic councils in the development of rural entrepreneurship (Case study: Bahabad, Yazd province). Rural Res Quarterly, 2(1): 93-114.

Hosseini SM, Sharifzadeh A, Akbari, M. 2009. Causes, effects and management mechanisms of drought crisis in rural and nomadic communities in southeastern Iran as perceived by agricultural/rural managers and specialist. J Hum Ecol, 27(3): 189-200.

Iranian Bureau of Statistics. Statistical center of Iran. 2021. URL: https://www.amar.org.ir/ (access date: May 01, 2021).

Jalali AA, Okhovvat MR, Okhovvat M. 2011. A new applicable model of Iran rural e-commerce development. Procedia Comp Sci, 3: 1157-1163.

Kalantari K, Shabanali Fami H, Asadi A, Qasemi I, Chubchian S. 2008. Major challenges of Iranian rural communities for achieving sustainable development. American J Agri and Biol Sci, 3(4): 724-728.

Keshavarz M, Karami E, Vanclay F. 2013. The social experience of drought in rural Iran. Land Use Policy, 30: 120-129.

Lahsaeizadeh A. 2007. Iran sociology of agriculture (In Persian). Tehran. Samt Publication of Iranian Human
Sciences Universities. 2007: 52-53.

Long H, Zou J, Pykett J, Li Y. 2011. Analysis of rural transformation development in China since the turn of the new millennium. App Geograp, 31: 1094-1105.

Marsden T, Sonnino R. 2008. Rural development and the regional state: Denying multifunctional agriculture in the UK. J Rural Stud, 24: 422-431.

Masoudi M, Yousefi M, Behbahani N. 2018. Hazard assessment of climate changes in south Khorasan province, Iran. EQA Environ Qual, (29): 29-39.

National Drought Warning and Monitoring Center (NDWMC). 2021. Periodical reports on the average amount of rainfall in Iran (In Persian). URL: https://ndc.irimo.ir/far (access date: April 12, 2021).

Nooripoor M, Shahvali M. 2011. Evaluation of rural sustainability criteria of dena county based on a communication view: the application of AHP. Rural Res Quart, 2(1): 63-92.

Park M, Stokowski PA. 2009. Social disruption theory and crime in rural communities: Comparisons across three levels of tourism growth. Tourism Manag, 30: 905-915.

Stockdale A. 2006. Migration: Pre-requisite for rural economic regeneration? J Rural Stud, 22: 354-366.

World Bank. 2020. Annual Report 2020. Supporting Countries in Unprecedented Times. URL: https://www.worldbank.org/en/about/annualreport\#anchor-annual (access date: May 12, 2021).

Živkovic D, Jelic S, Rajic Z. 2009. Agricultural extension service in the function of rural development. European Association of Agricultural Economists (EAAE), 113th Seminar, December 911, 2009, Belgrade, Serbia, pp: 517-525. 